\title{
A systematic review of indicators to assess the sustainability of road infrastructure projects
}

\author{
Gede B. Suprayoga ${ }^{1,2^{*}}$, Martha Bakker ${ }^{3}$, Patrick Witte ${ }^{2}$ and Tejo Spit $^{2}$
}

\begin{abstract}
Background: This study aims to examine to what extent sustainability has been incorporated into assessments of road infrastructure projects. It identifies promising approaches that include indicators reflecting core sustainability criteria, determines criteria that were insufficiently covered as indicators, and develops an integrated indicator set covering all criteria.

Methods: A systematic review was performed to obtain all related papers/reports in two academic databases: Scopus and Web of Sciences. The indicators extracted from papers/reports were first coded, then evaluated by using quantitative and qualitative content analysis.

Results: The project appraisal methods for decision-making is found to be a promising approach, covering more extensive criteria than others. Two criteria - namely adaptation and precaution and intergenerational equity - were hardly ever adopted as indicators. Ten main groups of indicators were extracted to construct an integrated set incorporating all core criteria.

Conclusions: Some criteria appear to have become mainstream, while others deserve attention. The safest choice is to combine methods/tools or to adopt the integrated set developed for exhaustive criteria inclusion.
\end{abstract}

Keywords: Sustainability criteria, Impact assessment, Cost-benefit analysis, Cluster analysis, Intergenerational equity

\section{Introduction}

Since the late 1980s, the emergence of the sustainable development concept has sparked interest from academia, government agencies, business organizations, and civic communities in developing a tool to help decisionmaking towards sustainability, called sustainability assessment (SA). SA refers to "a methodology that can help decision-makers and policy-makers decide what actions they should take in an attempt to make society more sustainable" ([15], p. 9). The main aim of SA is to ensure that plans and activities make an optimal contribution to sustainable development [82]. SA has increasingly become a common practice in various areas, such as product, policy, and institutional appraisals [70], as

\footnotetext{
* Correspondence: gede.budi@pusjatan.pu.go.id; g.b.suprayoga@uu.nl ${ }^{1}$ Institute of Road Engineering, Ministry of Public Works and Housing, A.H. Nasution 264, Bandung, Jawa Barat 40294, Indonesia

${ }^{2}$ Department of Human Geography and Spatial Planning, Utrecht University, Princentonlaan 8a, Utrecht, Utrecht 3584CB, The Netherlands

Full list of author information is available at the end of the article
}

well as in project evaluations [8]. As a concept, sustainability generally denotes a balance of economic, social, and environmental goals with a long-term (intergenerational) concern $[34,70]$.

In transportation projects, SA is applied to evaluate whether a project "contributes to favor economic development and fulfill the transportation needs of the society in a manner consistent with ecological and human values" ([8], p. 642). SA is an advanced methodology to ensure that decision-making is comprehensive and inclusive, meaning that it covers all three dimensions/pillars of sustainable development (i.e., environmental, social, and economic dimensions), including the indirect effects $[37,70]$. Political ambition can play a huge part in the planning of road projects. Such projects have vital roles in enhancing regional growth and economic competitiveness, especially in developing countries [17]. However, environmental aspects are relatively neglected and frequently only incorporated later on. Traditional impact 
assessment tools are often solely concerned with the environmental dimension, while the social and economic dimensions are less often considered (see Fischer [23] for strategic environmental assessment of transportation projects). This paper focuses on road infrastructure projects because of their impacts on the environment and society $[30,50,83]$. These projects are often key drivers of landscape transformations, habitat fragmentation, and societal change on both global and local scales [26, 67], with impacts lasting for long periods (e.g., [22, 72]) and producing intergenerational consequences (e.g., [32, 52]). Therefore, a better inclusion of sustainability dimensions is needed.

Bueno et al. [8] categorized methods and tools for the SA of transportation projects into three distinct approaches: (1) project appraisal methods for decisionmaking, (2) techniques for impact assessment, and (3) sustainability assessment methodologies. These approaches often adopt generic indicators that allow for uniform application in different situations. The purpose of these indicators is to identify trends, predict problems, set targets, evaluate solutions, and measure progress [51]. The indicators also serve as a compass for desirable development paths and communicate knowledge through the use of specific variables. The investigation of indicators in the SA of road infrastructure projects can provide general insights into whether a project and its components are contributing to sustainability. First, these approaches differ in their application of the indicators with regard to focus, number of attributes, and the methodological concepts (and frameworks) used [34]. Second, the interpretation of indicators varies concerning what sustainability means and which indicators to include [5].

After years of deliberation and experimentation, "it is not difficult to discern a limited number of common themes and broadly accepted general positions" ([29], p. 95) to interpret sustainability. Gibson et al. [29] developed eight basic requirements to attain greater sustainability that highlight the main criteria/aspects in SA. Based on these criteria/ aspects, this study examined the indicators for the SA of road projects in academic papers. Bond and Morrison-Saunders [5] suggest that, at present, SA seems prone to manipulation to suit particular discourses. This paper therefore provides a starting point for the development of an inclusive and balanced use of indicators. Such an effort can avoid the tendency to promote a specific frame of outcomes (such as economic growth instead of societal wellbeing) in the SA of road infrastructure projects. The primary research question (RQ) was: To what extent have sustainability criteria/aspects been incorporated as indicators to assess road infrastructure projects? Three sub-RQs were also formulated:
(1) Which sustainability criteria have the papers already included as indicators to assess road infrastructure projects? Is there a robust assessment approach based on the inclusion of these criteria?

(2) Which sustainability criteria are sufficiently or insufficiently covered as indicators in the examined papers?

(3) How can an integrated indicator set be developed and be further implemented to assess the sustainability of road infrastructure projects?

In order to answer the RQs, both quantitative and qualitative research methods were employed. A systematic literature search was conducted in two databases, Scopus and Web of Sciences. The following section outlines the theoretical framework. This is followed by the research methods.

\subsection{Theoretical framework}

\subsubsection{Approaches to the sustainability assessment of road infrastructure projects}

Scholars distinguish SA approaches differently. Sala et al. [70] categorize them according to the level of integratedness, ranging from a general method for decision support (such as multicriteria analysis and fuzzy analysis) to a more integrated tool/method (such as a genuine progress indicator or lifecycle sustainability assessment). De Ridder et al. [13] divide the approaches based on their potential role in the assessment phases: (i) participatory tools, (ii) scenario tools, (iii) multicriteria tools, and (iv) accounting and model tools. Bueno et al. [8] classify the methods and tools in the SA of transportation projects into three distinct approaches: (i) project appraisal methods for decision-making, (ii) techniques for assessing impacts, and (iii) sustainability assessment methodologies. This study adopted Bueno's classifications to investigate how SA is applied to guide decision-making in different project stages (i.e., planning, construction, usage) in order to capture various sustainability elements of road infrastructure throughout its lifecycle. The first approach has been extensively used by decisionmakers to plan road projects. Some of the tools in the third approach, such as the rating system tool, have now become popular [33].

1.1.1.1 Project appraisal methods for decisionmaking This approach is employed as an ex-ante evaluation to compare and select alternatives once it has been decided to implement a road project. Two methods are included in this approach. First, cost-benefit analysis (CBA), which supports sustainability by providing a "tangible and rational" judgment of the benefits and costs associated with alternative versions of a project [12]. CBA is based on the monetary values of user benefits (e.g., travel time savings) and other "negative" effects (e.g., energy consumption, 
resource use, and $\mathrm{CO}_{2}$ emissions). The second method is multi-criteria analysis (MCA). By using this method, several criteria - including those that are difficult to monetize and quantify - can be considered simultaneously [4]. MCA can cover project impacts comprehensively (i.e., the environmental, social, and economic impacts) and enable the involvement of stakeholders through the inclusion of their subjective judgments [64].

\subsubsection{Techniques for assessing environmental/social} impacts The second approach is aimed at quantifying the environmental efficiency of road projects [76]. Life-cycle assessment (LCA) is a technique used to assess the environmental impacts of a product, activity, or process (mostly in construction and operation stages). It is deployed to evaluate the sustainability performance of the whole project cycle, from cradle to grave (material extraction, manufacturing, transportation and distribution, utilization and maintenance, energy consumption, and waste handling) [73]. Second, social LCA (SLCA) was developed to incorporate social impacts in LCA [41]. This method - which is often called a social impact assessment - quantifies the social and distributional effects of projects throughout their lifecycles. Bueno et al. [8] argue that SLCA uses a broad definition of social impacts, but still lacks a specific framework to guide implementation.

1.1.1.3 Sustainability assessment methodologies The sustainability assessment methodologies approach is an expost project evaluation, aimed at assessing full accounts of project effects based on best practices. Bueno et al. [8] elaborate it into (i) rating systems and certification, and (ii) frameworks, models, and guidelines. First, the rating system and certification contain a collection of best practices to incorporate sustainability into road projects [49]. This tool is associated with a standard metric of points or credits that are used to evaluate and compare the sustainability elements of projects (e.g., pollutant loading in stormwater runoff, pavement design life, recycled material uses, pedestrian access). The rating system often comprises a self-evaluation mechanism developed for civil infrastructure projects, e.g., Greenroads, GreenLites, I-LAST, INVEST, and BE2ST-InHighways. The second category has a much broader scope and includes software tools for modelling and forecasting. Some of the tools have already been extensively applied, such as the UK Department of Transport Analysis (Web TAG) and Scottish transport appraisal guidance (STAG). These tools are deployed to (i) to represent best practices, (ii) provide expert advice for transportation projects, and (iii) establish criteria for assessing options. Therefore, tools in this approach use criteria to provide information about best practices and procedures related to ideal road projects and to improve road sustainability performance based on the assigned criteria [8].

\subsubsection{Core sustainability criteria for evaluating indicators}

Numerous sustainability criteria can be extracted from literature to examine indicators in SA. The literature provides criteria for extensive areas of practice, including agricultural undertakings [2], urban development [14], nature conservation [35], and spatial planning [63]. However, none of the criteria found is explicitly used for assessing road infrastructure projects. The criteria of Gibson et al. [29] are used here to develop what they refer to as "a minimal set of core [sustainability] requirements" (p. 95) and "key changes needed for progress towards sustainability" (p. 115). The criteria are elaborated into (i) socio-ecological system integrity, (ii) livelihood sufficiency and opportunity, (iii) intragenerational equity, (iv) intergenerational equity, (v) resource maintenance and efficiency, (vi) socio-ecological civility and democratic governance, (vii) precaution and adaptation, and (viii) immediate and long-term integration. Based on these criteria, this paper gauges whether approaches and indicators in the SA of road infrastructure projects have already considered sustainability in implementation.

Gudmundsson et al. [34] distinguish three aspects of indicators for transportation development, namely (i) dimension, (ii) comprehension, and (iii) staging/position. The "dimension" refers to the movement of the indicators (in space and time) to illustrate the importance of contexts in SA. The comprehension of indicators conveys an inclusion of information about what needs to be measured, for example, sustainability pillars (i.e., economic, social, and environmental). The staging presents activities at different stages (i.e., design, planning, construction, usage) that the indicators support to achieve the sustainability of projects. The sustainability criteria and aspects of indicators are listed in Table 1. The criterion immediate and long-term integration is omitted from the list because it includes cross-cutting criteria that should be evaluated at once.

Table 1 was also used to extract detailed indicators from the reviewed papers. The following section explains the research methods used to investigate the approaches, the criteria, and the indicators.

\section{Methods}

\subsection{Selection and categorization of papers}

A systematic literature search was conducted by using two academic databases - Scopus and the Web of Sciences - on June 24 and 25,2019 . The search strategy was initiated by identifying diverse terms that may refer to SA in the databases, such as "sustainability appraisal," "sustainability impact assessment," "sustainability evaluation," and "integrated assessment" (e.g., $[28,37,63]$ ) (Table 2). Both the singular and the plural form of these terms were searched for.

In this first selection, 490 papers were extracted by using the key search terms in Table 2. Papers representing assessments of other infrastructure projects, such as waterways, energy, and railways, were excluded from our selection. We 
Table 1 Core sustainability criteria (a1-g4) and indicator aspects (h-j) to evaluate the papers (based on [28, 29, 34])

\begin{tabular}{|c|c|c|c|}
\hline No. & Criteria/aspects & Code & Description/Example of Indicators \\
\hline \multirow[t]{2}{*}{1.} & \multirow[t]{2}{*}{ Socio-ecological system integrity } & a1 & $\begin{array}{l}\text { Build human-ecological relations to establish and maintain the long-term integrity of socio- } \\
\text { biophysical systems, e.g., reducing barrier effects of species, avoiding species habitat fragmentation. }\end{array}$ \\
\hline & & a2 & $\begin{array}{l}\text { Protect irreplaceable human and ecological life support functions upon which human and } \\
\text { ecological wellbeing depend, e.g., avoiding land-use change of agriculturally valuable areas, protection } \\
\text { of water bodies. }\end{array}$ \\
\hline 2. & $\begin{array}{l}\text { Livelihood security and } \\
\text { opportunity }\end{array}$ & $b$ & $\begin{array}{l}\text { Ensure that everyone and every community has a decent life and that everyone has opportunities } \\
\text { to seek improvements in ways that do not compromise future generations' possibilities for } \\
\text { sufficiency and opportunity, e.g., enhancing cost-efficient movement of goods and people, improving } \\
\text { access to jobs/employment. }\end{array}$ \\
\hline 3. & Intra-generational equity & c & $\begin{array}{l}\text { Ensure that sufficiency and effective choices for all are pursued in ways that reduce gaps in } \\
\text { sufficiency and opportunity (and health, security, social recognition, political influence, etc.) between } \\
\text { the rich and the poor, e.g., providing walking and cycling facilities for vulnerable groups of people, } \\
\text { improving affordability of road-based transportation services. }\end{array}$ \\
\hline 4. & Intergenerational equity & $d$ & $\begin{array}{l}\text { Preserve or enhance the opportunities and capabilities of future generations to live sustainably, e.g., } \\
\text { reducing road traffic injuries in children. }\end{array}$ \\
\hline \multirow[t]{3}{*}{5.} & \multirow[t]{3}{*}{$\begin{array}{l}\text { Resource maintenance and } \\
\text { efficiency }\end{array}$} & e1 & $\begin{array}{l}\text { Ensure sustainable livelihoods for all, while reducing threats to the long-term integrity of socio- } \\
\text { ecological systems by reducing extractive damages, e.g., utilizing locally obtained materials to reduce } \\
\text { energy consumption, reduction of water use in construction. }\end{array}$ \\
\hline & & e2 & $\begin{array}{l}\text { Avoid waste production, e.g., reducing traffic emissions }\left(\mathrm{NO}_{x}, \mathrm{CO} \text {, and } \mathrm{CO}_{2}\right) \text { in construction and } \\
\text { operation. }\end{array}$ \\
\hline & & e3 & $\begin{array}{l}\text { Cut overall material and energy use per unit of benefit, e.g., reusing pavement sections for } \\
\text { reconstruction. }\end{array}$ \\
\hline \multirow[t]{3}{*}{6.} & \multirow[t]{3}{*}{$\begin{array}{l}\text { Socio-ecological civility and } \\
\text { democratic governance }\end{array}$} & f1 & $\begin{array}{l}\text { Improve the capacity, motivation, and habitual inclination of individuals, communities, and other } \\
\text { collective decision-making bodies to apply sustainability requirements through more open and } \\
\text { better-informed deliberations, e.g., participating communities in assessments and decision-making, con- } \\
\text { formance with standards and requirements (e.g., technical, environmental, social). }\end{array}$ \\
\hline & & $f 2$ & $\begin{array}{l}\text { Foster reciprocal awareness and collective responsibility, e.g., improving trained personnel and } \\
\text { awareness of sustainability. }\end{array}$ \\
\hline & & f3 & $\begin{array}{l}\text { Strive for the more integrated use of administrative, market, customary, and personal collective } \\
\text { decision-making practices, e.g., integrating project plans with the spatial plans and environmental } \\
\text { management plan. }\end{array}$ \\
\hline \multirow[t]{4}{*}{7.} & \multirow[t]{4}{*}{ Precaution and adaptation } & g1 & Respect uncertainty, e.g., providing stormwater treatment with a higher level of output quality. \\
\hline & & g2 & $\begin{array}{l}\text { Avoid even poorly understood risks of severe or irreversible damage to the foundations of } \\
\text { sustainability, e.g., avoiding disaster-prone areas (e.g., erosion, landslide, other natural hazards). }\end{array}$ \\
\hline & & g3 & $\begin{array}{l}\text { Plan to learn, e.g., improving individuals and organizations' learning capacities to mitigate cross-scale } \\
\text { effects. }\end{array}$ \\
\hline & & g4 & $\begin{array}{l}\text { Manage for adaptation, e.g., reducing run-off from pavement areas, providing tree covers to reduce heat } \\
\text { gains of paved areas. }\end{array}$ \\
\hline 8. & Complete staging & h & $\begin{array}{l}\text { The reviewed papers cover materials, energy, and workflows/processes involved in projects } \\
\text { throughout the lifecycle (i.e., design, planning, construction, usage). }\end{array}$ \\
\hline 9. & Comprehension of pillars & i & The examined paper covers all sustainability pillars (i.e., social, economic, and environmental). \\
\hline 10. & Dimension (time, space) & j & The examined paper addresses project-context specificity based on time and space (location). \\
\hline
\end{tabular}

also excluded papers on small or fragmented elements of road infrastructure (e.g., pavements, roadside facilities) and technological assessments (e.g., innovative construction materials, intelligent systems) to concentrate on the road project scope. Next, we filtered out papers identified as similar reports. Finally, a dataset consisting of 31 papers was analyzed (Fig. 1). The papers in the dataset originated from the disciplines of engineering, ecology, environmental sciences, geography, and social sciences. Most (15) papers concern European countries, namely Germany, UK, Spain, France, Denmark, Croatia, Poland, and Hungary. North American countries constituted cases in eight papers. Seven papers originated from Asian countries and one from an African country.

We extracted all indicators found in the examined papers. We categorized the indicators into core sustainability criteria and elaborated on the criteria based on the descriptions given in Table 1. The number of criteria applied was also noted.

\subsection{Analysis methods}

Both a quantitative and a qualitative method were used to examine the paper set. To answer the first sub-RQ, we grouped papers by using a cluster analysis, based on the 
Table 2 Synonyms and replacement words as key search terms

\begin{tabular}{|c|c|c|}
\hline Sustainability & Sustainability assessment & Road infrastructure projects \\
\hline sustainable development & assessment method & transport infrastructure \\
\hline \multirow[t]{7}{*}{ sustainable } & assessment tool & road \\
\hline & assessment approach & highway \\
\hline & sustainability appraisal & freeway \\
\hline & integrated assessment & roadway \\
\hline & sustainability impact assessment & motorway \\
\hline & sustainability-based assessment & street \\
\hline & sustainability evaluation & transport project \\
\hline
\end{tabular}

coded description from "a" to "j" in Table 1. For the second sub-RQ (Which criteria are sufficiently or insufficiently covered as indicators in the examined papers?), we counted the number of papers using the criteria in indicators. The third sub-RQ was based on qualitative content analysis.

\subsubsection{Quantitative content analysis}

The clusters were formed using a complete-linkage technique, namely an agglomerative hierarchical clustering technique that is appropriate for the analysis of a relatively small sample size [59]. Papers with similar characteristics were combined into a cluster [58]. The application of this technique has more flexibility because no predefined number of clusters should be set. It allows a more intuitive way to define the number [75] by exploring the similarity of the characteristics of the dataset in detail based on the criteria included. The cluster set was represented in a tree diagram (a "dendrogram"). There is no exact rule about defining the sample size [59]. Dolnicar [18] observes this size ranging

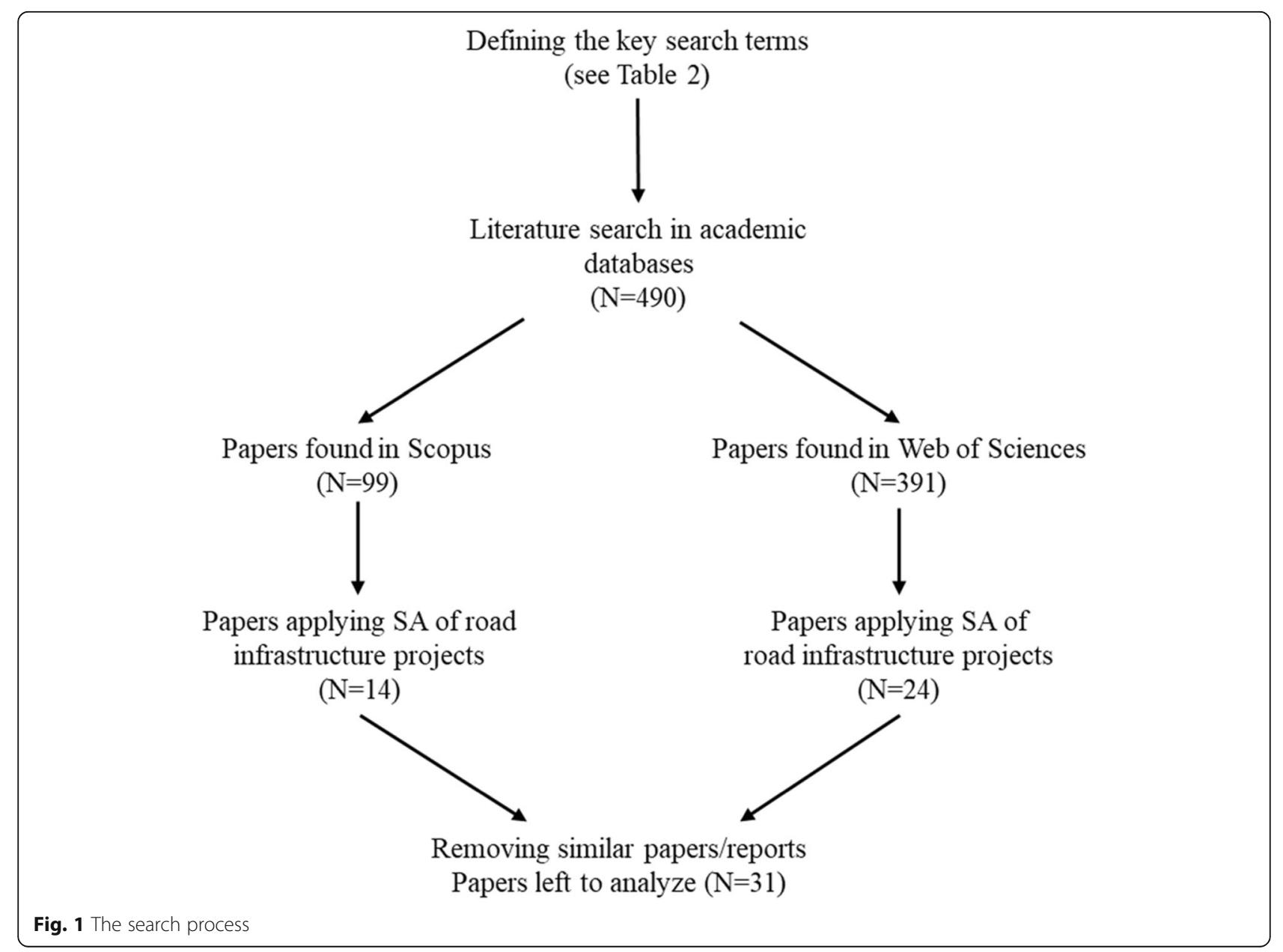


from 10 to 20,000 elements and, by using Pearson's and Spearman's correlation, concludes that "even very small sample sizes are used for clustering in very high dimensional attribute space" (p. 2). The size may be less relevant to consider since the analysis works with an unknown structure (see [19]).

We used the descriptions in Table 1 to establish the coverage of the criteria. A descriptive statistic was applied to represent mode and the percentage of the criteria. Next, categorical principal component analysis (CatPCA) was performed to evaluate the correlation between the criteria. We used the Varimax rotation method to examine the correlation between the criteria and visually present their proximity so that they could be grouped into smaller criteria. The method maximizes the sum of the variances of the squared loadings (or squared correlations) within fewer dimensions [56]. The result was a bi-plot informing the dimensions of correlated criteria.

\subsubsection{Qualitative content analysis}

We started the analysis by extracting all indicators found in the examined papers. All indicators were grouped by using a configurative method [31] to develop an integrated set. If an indicator did not match a specific group, a new group was added as complementary to the set. To avoid redundancies, we also investigated whether the extracted indicators addressed specific criteria. Lastly, we compared the findings with the result of the quantitative content analysis.

\section{Results}

\subsection{Results 1: sustainability criteria in the SA of road infrastructure projects}

Figure 2 presents the outcome of the cluster analysis. Four major clusters were identified. Cluster 1 contains the largest number of papers $(n=21)$ with no more than seven criteria adopted in each paper. This cluster can be divided into two smaller groups (sub-clusters 1a and 1b). Sub-cluster 1a contains all papers using the criteria socio-ecological system integrity (a1) and livelihood security and opportunity (b). Subcluster $1 \mathrm{~b}$ contains papers that include indicators that apply the criteria socio-ecological system integrity (a1), resource maintenance and efficiency (e3), and comprehension of pillars (i).

Only three papers were found in cluster 2 , and only two in cluster 3 . These clusters included indicators with more exhaustive and diverse criteria than the other clusters. Finally, cluster 4 comprises five papers with indicators that adopt three similar criteria: socio-ecological civility and democratic governance ( $\mathrm{f} 1$ and $\mathrm{f} 3$ ) and comprehension of pillars (i).

In Fig. 2, the clusters represent the diverse approaches deployed. Cluster 1 contains papers applying all three approaches. One sub-sub-cluster (cluster 1b.1) mainly comprises papers deploying "techniques for impact assessment."
All papers in sub-cluster 2 and cluster 3 apply "project appraisal methods." In cluster 4, all papers deploy "sustainability assessment methodologies." Considering that clusters 2 and 3 adopt more criteria as indicators, the approach deployed can be considered more comprehensive than the others. Papers in clusters 2 and 4 successfully adopt the criterion comprehension of pillars (i).

The bar plot in Fig. 3 shows the number of papers that adopt the criteria in Table 1 as indicators. Criteria al and b are the most used criteria, adopted in 29 of the 31 papers (93.5\% of the papers). The criterion socio-ecological system integrity (a1 and a2) is used in 28 and 18 papers, respectively. The least adopted criteria are precaution and adaptation (g3) and intergenerational equity (d) (each appear in only one paper). On average, seven criteria are adopted as indicators in the examined papers.

Figure 4 depicts two principal components (PCs) that position the proximity between the sustainability criteria/aspects and the approaches. The line direction (vector) visualizes the correlation of the criteria/aspects with the PCs. A strong correlation is shown by the vector proximity that corresponds to the PCs. PC1 and PC2 represent $19.6 \%$ and $16.2 \%$ of the total variance, respectively. Four criteria strongly correlate with $\mathrm{PC} 1$, namely: socio-ecological system integrity (a2), resource maintenance and efficiency (e2), comprehension of pillars (i), and dimension (j). This implies that the criteria/ aspects can be grouped into fewer criteria. However, these criteria are in a negative correlation with "techniques for impact assessment," meaning that they are hardly included as indicators in this approach.

Figure 4 shows that the criteria intergenerational equity (f2) and precaution and adaptation (g4) and the "sustainability assessment methodologies" approach strongly correlate with PC2. Both the criteria and the approach are in negative correlation, meaning that the criteria are less adopted as indicators in the approach. The other criteria are more independent than previously mentioned, so they are grouped into a much smaller number of criteria. The figure also shows that the "project appraisal methods" approach has a similar direction to the criterion 'precaution and adaptation (g4), implying that the approach consistently adopts the criterion. Another finding is that the "techniques for impact assessment approach" has a closer relationship with the aspect of complete staging (h).

\subsection{Results 2: sustainability indicators extracted from the examined literature}

The qualitative content analysis revealed 10 major groups of indicators in the examined papers (see Appendix 1 for details). These groups categorized the assessment indicators into: (1) Mitigation of species habitat fragmentation and land use management, (2) Mobility and accessibility improvement, (3) Pollution (soil, water, 


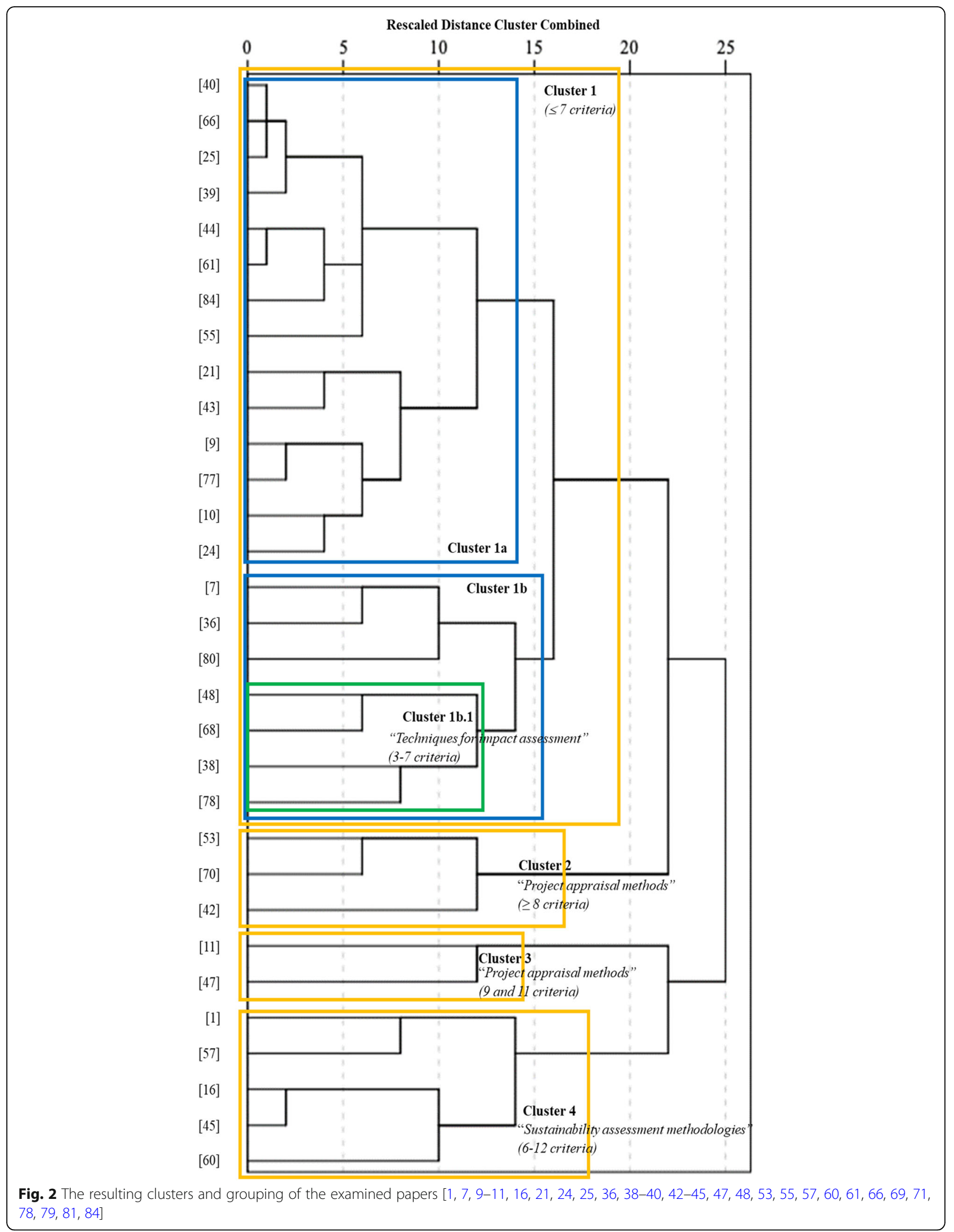




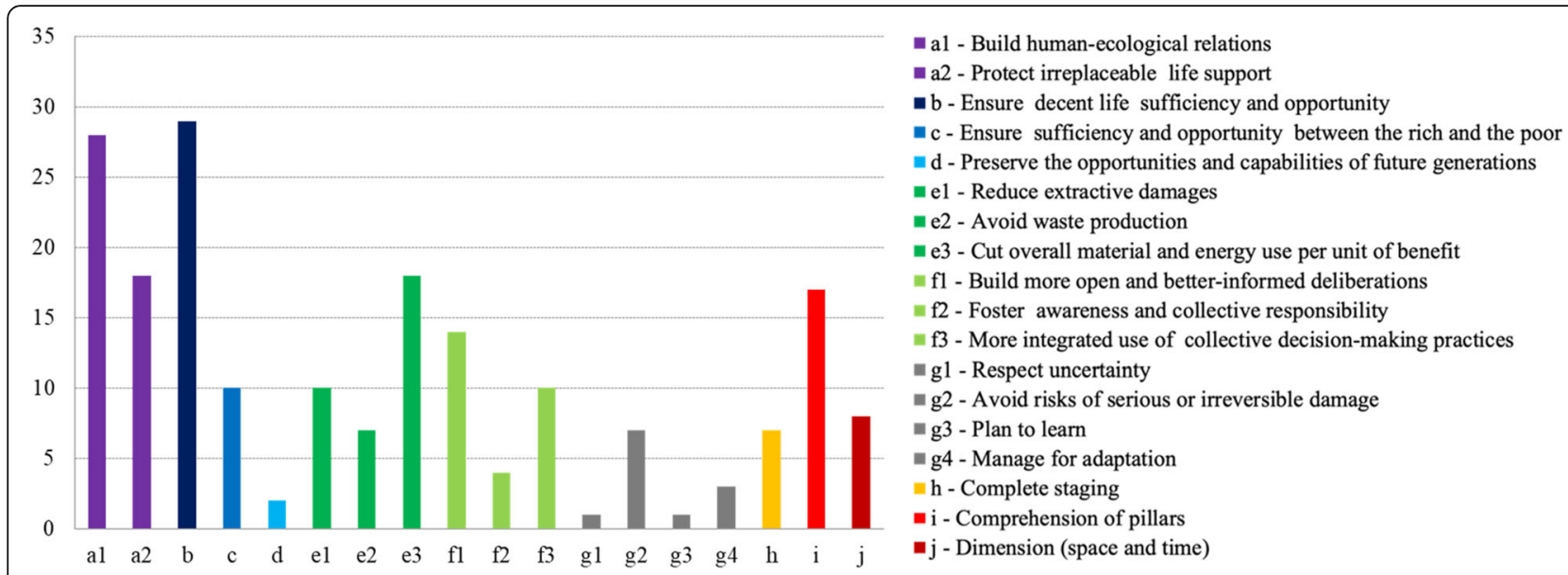

Fig. 3 Bar plot showing the sustainability criteria addressed as indicators in the papers reviewed

air, light, noise) prevention, (4) Climate change adaptation and resilient infrastructure, (5) Community livability improvement, (6) Resource efficiency, (7) Societal wellbeing and equity (both intrageneration and intergeneration), (8) Integrative planning and decision-making, (9)
Technological utilization for impact mitigation, and (10) Context-sensitive development.

The findings show that the indicators adopted are not limited to environmental protection aspects (mitigation of habitat fragmentation, land use management, pollution

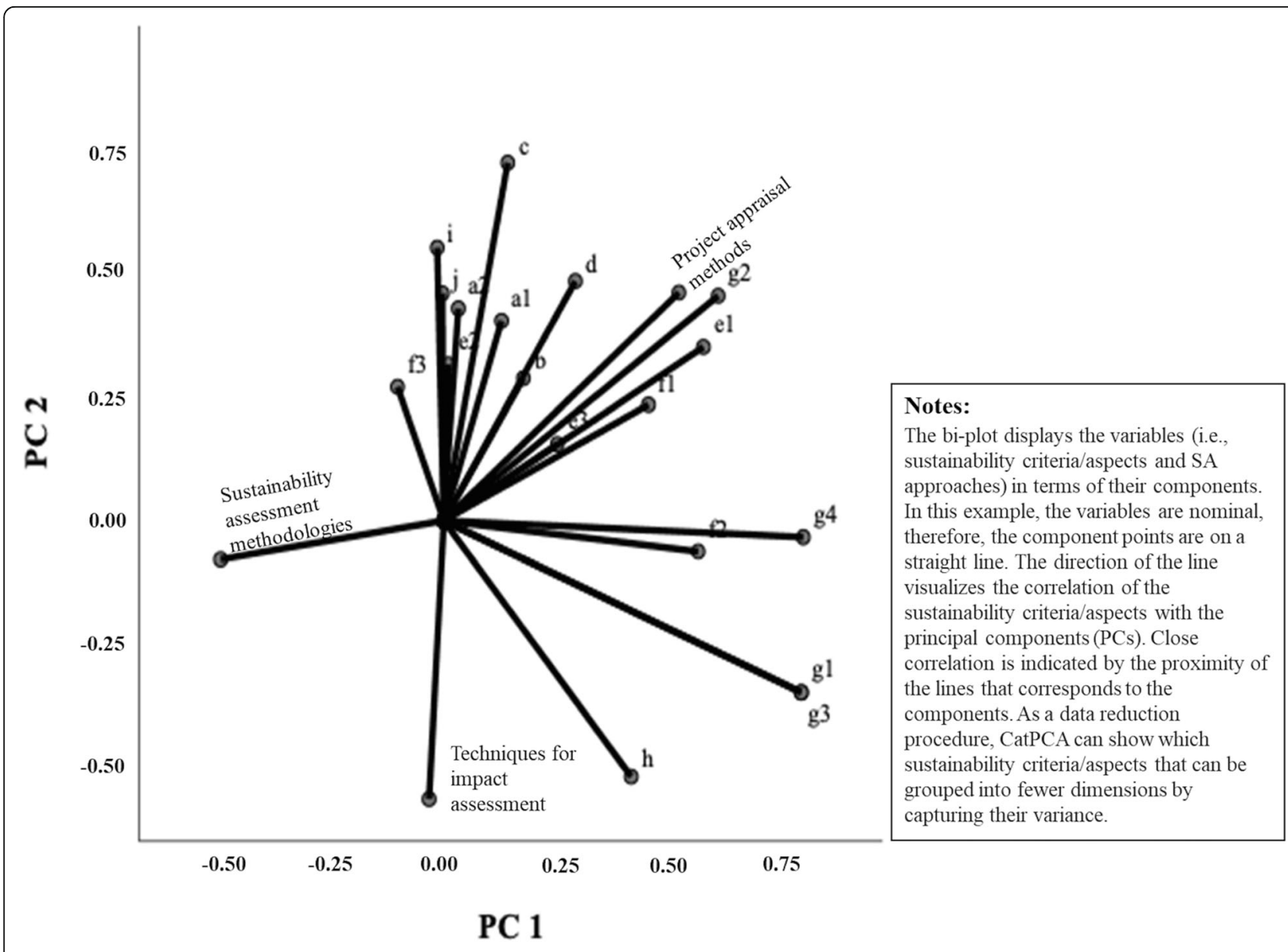

Fig. 4 The bi-plot of CatPCA derived from the coded descriptions in Table 1 
prevention, and resource efficiency), but also cover socioeconomic aspects (community livability, societal wellbeing, and equity) - thus revealing the importance of integrative decision-making to achieve sustainability goals. Two distinct groups of indicators were found concerning the utilization of technology for impact mitigation and context-sensitive development. The finding implies that both process and context are vital in the SA of road projects. The results show that road projects are assessed against various indicators and that some indicators are used more often than others. Without considering the adoption of the sustainability criteria in Table 1, the SA of road infrastructure projects may serve specific discourses, such as the mitigation of ecological impacts. The following section discusses this matter.

\section{Discussion}

Based on the results, this section discusses i) the robust SA approach to road infrastructure projects, ii) the criteria sufficiently or insufficiently covered, and iii) the development and operationalization of an integrated indicator set.

\subsection{Finding a robust approach to assess road infrastructure projects}

This paper shows that although considerable efforts have been made to include sustainability criteria in SA approaches to road infrastructure projects, none of the approaches includes all criteria/aspects. This finding substantiates the conclusion drawn by Bueno et al. [8] that "none of the [existing] methods and tools can be used to carry out a holistic appraisal." Fig. 2 shows that two clusters (clusters 2 and 3) use a more exhaustive set of criteria than the others. Both clusters contain papers applying "project appraisal methods" that consistently adopt more than eight criteria. MCA, in particular, identifies criteria, evaluates alternatives, assigns weighting coefficients to the criteria, and finally evaluates sustainability criteria by ranking the alternatives [4]. The method allows decision-makers to account for complex problems within biophysical and socioeconomic systems through the inclusion of multiple elements using the criteria (see [46]). Pope and Morrison-Saunders [64] also argue that MCA allows many considerations to be incorporated into the decisions and enables diverse stakeholder perspectives to consider transparently. The "project appraisal methods" approach therefore has the potential to enhance project performance, as the chance of incorporating sustainability improves in the early part of the project lifecycle [68].

Both the "project appraisal methods" and the "sustainability assessment methodologies" approach have become useful to incorporate all pillars of sustainability, as found in clusters $1 \mathrm{~b}$ and 3 . The rating system tool is mostly applied to "rank and score projects against sustainability performance by putting economic, environmental, and social aspects together" ([8], p. 632). The "techniques for impact assessment" approach tends to include the criterion complete staging (h).
The bi-plot result (Fig. 4) indicates that the approach and the criterion are closely correlated. This finding substantiates that LCA is better deployed to assess project sustainability performance with regards to the efficient use of material and energy throughout the lifecycle (reuse, recycling, recovery, and final waste handling). As few papers apply it, this finding is just a weak indication.

The cluster analysis also shows some problems with the deployment of the approaches. First is the lack of coherence use of criteria to develop indicators in the assessments. The selection of these indicators tends to be arbitrary. Gibson [28] suggests a sustainability test by using the core criteria set to distinguish whether the assessments are genuinely aimed at achieving sustainability. Second, none of the approaches can successfully include indicators based on the criteria/aspects in Table 1. The realistic way to include all criteria is to combine diverse approaches/methods, such as the combination of LCA and CBA. LCA can better assess the inter-temporal aggregation of impacts (intergenerational equity), while CBA covers thoroughly the sustainability pillars as the basis for identifying the project effects in monetary terms (e.g., [54]).

\subsection{Sustainability criteria fully covered/uncovered as indicators}

This paper demonstrates that the sustainability criteria have been varyingly incorporated as indicators. The two most frequently used criteria are socio-ecological system integrity and livelihood security and opportunity. The criterion socio-ecological system integrity is often used to develop indicators that refer to project effects across scales from climate change and ozone layer depletion at a global scale $[11,24,48,55$, $71]$, to soil and local water quality at a fine spatial scale [45, 60,81 . The criterion socio-ecological system integrity is associated with the indicators concerning the mitigation of species habitat fragmentation, land use management, and pollution prevention. The criterion livelihood security and opportunity is adopted to construct indicators related to the socioeconomic effects of projects. These indicators can be grouped into mobility and accessibility improvement, community livability $[9,16,24,45,48,55,57,84]$, and societal wellbeing and equity $[10,21,36,42,71]$. Several indicators concern intergenerational equity (e.g., direct and indirect effects on employment), and transportation costs are also derived from the criterion $[42,71]$.

Two criteria are the least covered as indicators in the examined papers. One is precaution and adaptation, which is aimed at evaluating whether irreversible damage and risks to people and the environment have been taken into account in projects (UNCED, 1992). A group of indicators reflects this criterion: resilient infrastructure and climate change adaptation. By using the criterion, indicators are developed to assess the ability of road infrastructure to withstand shocks and unpredicted 
events (e.g., climate disaster, earthquakes) [42]. Gibson et al. [29] identify the possible barriers to their incorporation: (i) unawareness of the assessor, (ii) cognitive uncertainty regarding the condition being assessed, and (iii) methodological difficulties. Salling and Pryn [71] suggest a certainty analysis in CBA to estimate future costs and possible changes in the value of benefit and cost ratios. Bueno and Magro [7] also recommend the application of sensitivity analysis in MCA to identify to what extent the geographical context of the projects has varied, resulting in different risks (and uncertainty) to consider in the assessments.

The second least adopted criterion is intergenerational equity. The criterion is used to evaluate the cross-generational effects of projects through indicators concerning societal wellbeing and intergenerational equity (e.g., long-term employment opportunities). The inherent methodological limitation is often blamed for the lack of inclusion. Gasparatos et al. [27] argue that most SA methods/tools focus only on economic efficiency, and not on equity. Bueno et al. [8] state that the "traditional" assessment methods/tools only identify impacts for limited time-horizons, most of which are intangible. Joumard and Nicolas [42] express the criticism that the typical linear accounting method (such as CBA) imposes a much lower present impact valuation, which is critical for future generations. Therefore, the components of the discount rate need to be reframed in such a way that the intergenerational inequity concerns of the projects can be included and evaluated, such as concerns about agricultural land losses and community disruptions. These findings show that pragmatism might play a role in the inclusion of the indicators. Therefore, a robust SA approach to road infrastructure projects based on the criteria included is still a long way off.

\subsection{Developing an integrated indicator set}

This study categorized assessment indicators in the examined papers into 10 main groups. These groups show that sustainable road infrastructure projects are reflected not only in the mitigation of environmental impacts, but also in the improvement of societal wellbeing and community livability. Some papers included indicators about processes to ensure that sustainability is achieved. Consequently, a group of indicators concerning integrative planning and decision-making was added to the set.

Two criteria - namely intergenerational equity and precaution and adaptation - were identified in one cluster, and the two are closely correlated (see Fig. 2). However, both are infrequently adopted as indicators, but can be incorporated in the SA of road projects by applying scenarios, adaptive management plans, and socioenvironmental risk estimations [42]. The criteria are further elaborated in two groups of indicators, that is, "resilient infrastructure and climate change adaptation" and "technological utilization for impact mitigation."

Three criteria - resource maintenance and efficiency, socio-ecological civility and democratic governance, and comprehension of pillars - were identified in a similar dimension and are highly correlated in the bi-plot (see Fig. 4). On the one hand, administrative and market arrangements (standards, regulations, and carbon markets) can enforce efficient uses of energy and materials in road construction and operation. On the other hand, efficiency can be achieved if these arrangements are available and used to guide decision-making if no conflicts are found between the arrangements and the actual implementation [24]. However, Bond and Morrison-Saunders [6] doubt that on their own, the arrangements will ensure effective implementation.

Better inclusion of the aspect of comprehension of the pillars can be made possible if inclusive decisionmaking is carried out [60]. This finding underlines that sustainability is not only about outcomes, but also about processes, such as stakeholder involvement, the coordination of responsible agencies, and sustainable funding mechanisms $[34,65]$. Therefore, integrative planning and decision-making are included as one distinct group of indicators.

Sustainability needs to take into account the aspect of dimensions (space and time) so that the assessment can differ according to the place and the social conditions [8]. The qualitative content analysis explored a group indicator that includes options and actions to harmonize road development with the surroundings; for example, roads are designed to suit local contexts (e.g., safe streets for school zones) and to meet local regulations and standards. In the examined papers, road infrastructure projects already take into account aesthetic, environmental, and art/culture/community values $[51,60]$.

\subsection{Operationalizing the indicator set}

The integrated indicator set provides a guideline on which indicators should be included in the SA of road projects or whether sustainability has already been considered. The full application of the set may be difficult because resource availability (e.g., money, funding, and data) and the complexity of the decision-making process can act as barriers. How should the indicators be chosen in actual assessments?

Some scholars suggest that a framework is needed as a constraining factor when choosing the appropriate indicators [20,34]. This framework maintains the link between the sustainability objective and the indicators applied to monitor progress. Svarstad et al. [77] show that frameworks tend to favor the particular discourses 
of the organizations that construct them. For example, the DSPIR (driver-state-pressure-impact-response) framework tends to focus on the pressure indicators (e.g., mobility improvement in congested regions) rather than the state or impact indicators (e.g., species habitat fragmentation and community disruption) [80]. Bell and Morse [3] suggest that the participation of affected stakeholders can obviate the selection bias and increase opportunities to incorporate multiple discourses in the indicators.

Still, the sustainability outcomes of road projects will depend on the tested alternatives and the baseline against which the individual indicators are applied. For example, if the aim of a proposed road passing through a protected forest is to connect isolated communities, an alternative policy may entail the construction of the road away from the forest, but lead to much longer travel times. Another alternative is to adopt indicators with regard to the mitigation of species habitat fragmentation. But this option may not be so beneficial to people's mobility and areal accessibility, or to intra-generational equity and societal wellbeing (improved access of community members to public services). Irrespective of the indicators chosen, the choice often depends on the decision makers offering contextually sensitive solutions that respect the local environmental and community values, and applying technologies that make the project less harmful to the surrounding area.

This study suggests that the SA of road infrastructure projects should prioritize the inclusion of indicators that can secure natural capital and manage its long-term changing state. Most of the examined papers acknowledge that negative impacts are inevitable and use indicators to illustrate these impacts (e.g., pollution prevention and technological utilization for mitigation). But the assessments are applied without testing whether any critical natural capital is lost or secured (see [80]). As a consequence, the criteria precaution and adaptation and intergenerational equity - both of which are less considered in the examined papers (Fig. 3) - need to be incorporated as indicators. By integrating these criteria, SA can identify those who are affected by the change of critical resource/capital and in what ways road infrastructure projects cause less damage to the environment.

\section{Conclusion}

This paper examined the extent to which the assessment of road infrastructure projects has considered sustainability through the inclusion of indicators closely associated with sustainability criteria in the literature. Some criteria appear to have become mainstream indicators, while others deserve attention.
None of the reviewed papers considers all criteria, probably for feasibility reasons, but also sometimes out of pragmatism. Special attention should be paid to the criteria precaution and adaptation and intergenerational equity. Both criteria are either tricky or inconvenient to elaborate as indicators. We therefore suggests that these criteria should be included as indicators more often in future applications. The safest choice is to follow the "methodological pluralism" argument (i.e., the combination of multiple methods/tools) [27] for an exhaustive criteria inclusion. Without considering the core sustainability criteria in Table 1, the development and implementation of indicators can become arbitrary and tend to serve particular discourses of outcomes [5]. The integrated indicator set presented here provides the full account of the discourses.

The advantage of using a systematic review is evidential with regard to transparency [62]. However, there are also drawbacks. First, in our case, relatively few papers were evaluated, raising the question whether the studied sample was sufficiently representative. Only a small selection of instances of the SA of road infrastructure projects are published in peer-reviewed scientific journals, and we have to bear in mind that these somehow deviate from the majority, which are published in the grey literature. For a paper to be accepted in a scientific journal, it needs to contain some innovative elements, such as the use of an innovative method or a new set of indicators. If that is indeed the bias of our sample, it suggests that the broader body of the literature is likely to be more "on the beaten track" than the papers evaluated here. This issue means that specific indicators are probably even more pronounced in the grey literature.

Future research should be able to elaborate further on the integrated indicator set. The set needs to be completed so that all sustainability criteria can be fully incorporated. The criteria intergenerational equity and precaution and adaptation require further elaboration, as do the ways in which frameworks can be constructed to better incorporate the criteria. Another research avenue is the investigation of distinct perspectives on sustainable development, namely the comprehensive and the sectoral view [34], which may influence the selection of these indicators. The use of the indicators also differs according to the scale of the assessments in which they are applied (e.g., global, regional, local, or neighborhood level). Context-specificity may determine how the indicators are selected. The present study shows that the SA of road infrastructure projects is not only a matter of technical deployment of the approaches, but also an integrated decision-making process [74]. Therefore, to improve effectiveness, not only must the approaches be advanced, but also the process and contextual barriers must be identified. 


\section{Appendix}

The integrated indicator set to assess the sustainability of road infrastructure projects.

\section{No. Main group of indicators/ Indicators \\ 1. Mitigation of species habitat fragmentation and land use} management

Reducing barrier effects on species; Avoiding species habitat fragmentation; Creating new species habitats beyond what the project is required; Protecting valuable habitats and natural (ecological) areas (e.g., wetlands, peat bogs, forest, semi-natural areas); Protecting endangered species and biodiversity; Protecting soil characteristics (e.g., mechanic, permeability, texture); Protecting green areas (e.g., avoiding deforestation and tree removal); Protecting landscape and human-made heritage; Avoiding irreversible damages to local ecosystems (e.g., fjord); Balancing earthwork quantities (cut and fill) during construction; Prioritizing native soils/materials for construction; Decreasing land-use changes (e.g., from forests to pavement areas); Avoiding productive land loss (e.g., best agricultural soils); Preserving water quality, capacity, and regime (e.g., keeping buffer between water body and road edge); Minimizing visual disturbance on surroundings.

2. Mobility and accessibility improvement

Reducing travel time; Decreasing road user's costs; Improving level of service; Improving accessibility to public services and other purposes (e.g., food shops, tourism, culture); Improving proximity to transits areas; Improving accessibility to disaster evacuation routes; Providing non-motorized transportation facilities for pedestrians and cyclists; Providing public transportation facilities (e.g., bus stops, train stations); Enhancing accessibility to public transportations; Enhancing goods and people movement (economic throughput and efficiency); Improving accessibility to employment in economic zones; Improving territorial cohesion and areal connectivity; Reducing impairments of traffic flow and driving comfort (e.g., congestion); Improving compatibility of diverse transportation modes.

3. Pollution (soil, water, air, light, noise) prevention

Reducing traffic emissions $\left(\mathrm{NO}_{x}, \mathrm{CO}, \mathrm{PM}>10, \mathrm{CO}_{2}\right)$ /improving local (and regional) air quality; Reducing light pollutions from traffics; Minimizing impacts on atmosphere (e.g., acidification potential (AP), eutrophication potential (EP), ozone depletion, smog); Minimizing/ controlling noise, vibration, dust, and light trespassing; Reducing materials wasted in construction; Providing on-site recycling and waste collection; Protecting watercourses (e.g., lakes) in construction.

4. Climate change adaptation and resilient infrastructure

Reducing run-off quantity; Improving stormwater quality treated; Reducing urban heat island (UHI) effects; Reducing greenhouse gas (GHG) footprints; Selecting local climate-oriented plants/trees; Avoiding prone disaster areas (e.g. erosion, landslide, and hazardous susceptibility areas) in construction; Anticipating future traffic demands and disaster risk assessments; Reducing stormwater vaults through provision of natural drainage systems; Providing low impact development (LID) (e.g., basins in planters and rain gardens) to manage infiltration of stormwater; Reducing heat gains (from pavement areas) through tree planting.

6. Community livability improvement

Avoiding natural and human capital losses because of traffic emissions; Providing/preserving views/scenery/vistas/scenic spots; Protecting archaeological and historic resources; Reducing accident risks in urban areas; Mitigating emission effects on human health (e.g. respiratory illness, cancer, premature deaths) and on urban ecosystem quality; Improving local perception on urban health quality (e.g., fine particulates and health-related emissions); Enhancing community cohesion; Increasing visual quality and art/culture/community values of neighborhoods; Avoiding on-street parking in urban areas.

\section{Appendix (Continued)}

No. Main group of indicators/ Indicators

7. Resource efficiency

Utilizing locally obtained materials for construction; Re-using pavement materials for construction; Selecting cost-effective design; Reducing space use for alignments; Reducing uses of non-renewable raw materials (e.g. fossil fuels); Utilizing non-renewable minerals (e.g. limestone, iron ore); Utilizing indigenous renewable energy (e.g., hydroelectricity); Improving energy efficiency in construction and operation; Reducing water uses in construction; Re-using stormwater for other purposes (e.g. irrigation).

8. Societal well-being and equity (both intrageneration and intergeneration)

Equitable environmental quality (from mitigating traffic emissions) in vulnerable groups of people (e.g., children, elderly, disabled); Enhancing regional growth and economic activities (e.g. business, jobs/employment, wages, property value); Enhancing fiscal impacts (e.g., public revenues); Reducing traffic injuries in vulnerable groups of people; Reducing pollution impacts to vulnerable groups of people (with their disproportionate effects in deprived areas); Promoting walking and cycling to improve general health; Improving perception on equity to decrease social tensions in resource allocation; Enhancing physical and social mobility for all people (to access, e.g. food, health care, friends, leisure, cultural, exercise); Reducing noise level to improve sleep quality and daytime sleepiness for children; Reducing travel costs to lower expenses for all households; Enhancing distributive effects of better connectivity to reduce spatial inequity; Providing transit and HOV access for all; Providing pedestrian and bicycle paths and dedicated access for vulnerable groups of people.

8. Integrative planning and decision-making

Applying road safety audit; Conformance with standards and requirements (e.g., technical, environmental, social); Disseminating information (public outreach) about the project sustainability (e.g., elements, technology); Participating/collaborating stakeholders and experts in the planning, construction, and usage phase (e.g. outcomes, strategic objectives, needs/mutual benefits, alternatives, facility upkeeps); Training personnel involved in the application of environmental sustainability programs; Educating public/personnel to increase awareness of sustainability; Hiring contractors having certified international standards in quality and environmental management systems; Providing contractors' warranty to ensure pavement durability; Integrating project funds in environmental impact mitigation; Improving consistency and coordination between project planning and regional (spatial) objectives; Enhancing crossinstitutional collaboration; Securing funds for maintenance; Integrating land use planning and environmental management; Integrating data, information, and models in planning and assessments; Improving individual and organizations' capacities to mitigate cross-scale impacts; Applying innovative delivery systems to incorporate sustainability.

9. Technological utilization for impact mitigation

Utilizing low impact development (LID) (e.g., permeable/porous pavement); Applying intelligent transportation system (ITS) solutions to manage traffic flows; Utilizing quiet pavement technology to reduce noise; Utilizing high-performance pavement (based on lifecycle assessment)/low-budget maintenance; Utilizing rapid and lean construction techniques; Utilizing precast/modular elements; Using low-energy lightings; Utilizing solar power sources in construction and usage; Applying climate-resistant designs and materials; Utilizing lowemission materials (e.g. warm mix asphalt); Utilizing low-emission equipment; Utilizing recycled materials; Utilizing data monitoring for water use in construction.

10. Context-sensitive development

Applying water-appropriate plantings to secure hydrological 


\section{Appendix (Continued)}

No. Main group of indicators/ Indicators

conditions; Applying context-sensitive landscape solutions (e.g., native vegetation and diverse plants); Applying context-sensitive \& consistent designs to improve safety (e.g., traffic calming in residentials, safe streets in educational zones); Adopting regulations and standards to suit with local contexts and to apply user-oriented solutions; Integrating project plans with local concerns (e.g., aesthetic, environmental, art/culture/community values, senses of place).

Source: Own elaboration based on the examined papers. Note: All groups of indicators are extracted based on the indicators included in the papers reviewed. The detailed indicators are collected and compared. If indicators were found to be more or less the same, they were treated as the same indicator. Units of these indicators have been left out to allow the merging of the indicators without omitting the exact meanings.

\section{Acknowledgements}

The authors would like to thank Professor Leonie B. Janssen-Jansen, who died in 2018, for commenting on the conceptual design of the manuscript that initiated a thorough examination of sustainability assessment of road infrastructure projects

\section{Authors' contributions}

GBS designed the study, analyzed both the quantitative and qualitative data, interpreted the data based on the sustainability criteria found in the literature, and wrote the whole manuscript sections. MB contributed to the interpretation of the quantitative analysis and drafted the discussion section about the sustainability criteria. PW interpreted the results of the qualitative analysis. TS conceptualized the manuscript design and contributed to synthesize the findings of the report. All authors read and approved the final manuscript.

\section{Funding}

This work was supported through the Indonesia Endowment Fund for Education (LPDP) grant (Nr. 20160222015432). The Ministry of Finance, Republic of Indonesia, granted the funding. The findings, interpretations, and conclusions presented in this article are entirely those of authors and should not be attributed in any way to the ministry.

\section{Availability of data and materials}

The list of datasets (or the list of papers) used and analyzed during the study are available from the corresponding authors on reasonable requests.

\section{Competing interests}

The authors declare that they have no competing interests.

\section{Author details}

${ }^{1}$ Institute of Road Engineering, Ministry of Public Works and Housing, A.H. Nasution 264, Bandung, Jawa Barat 40294, Indonesia. ${ }^{2}$ Department of Human Geography and Spatial Planning, Utrecht University, Princentonlaan 8a, Utrecht, Utrecht 3584CB, The Netherlands. ${ }^{3}$ Department of Environmental Sciences, Wageningen University and Research, Droevendaalsesteeg 3, Wageningen, Gelderland 6708PB, The Netherlands.

Received: 5 August 2019 Accepted: 4 February 2020

Published online: 03 April 2020

\section{References}

1. Barfod, M. B. (2018). Supporting sustainable transport appraisals using stakeholder involvement and MCDA. Transport, 33(4), 1052-1066. https://doi. org/10.3846/transport.2018.6596.

2. Becker, B. (1997). Sustainability assessment: A review of values, concepts and methodological approaches. Washington, DC: Consultative Group on International Agricultural Research/World Bank.

3. Bell, S., \& Morse, S. (2010). Sustainability indicators: Measuring the immeasurable? Landon: Earthscan.

4. Beria, P Maltese, L, \& Mariotti, I. (2012). Multicriteria versus cost-benefit analysis: A comparative perspective in the assessment of sustainable mobility. European Transport Research Review, 4(3), 137-152. https://doi.org/ 10.1007/s12544-012-0074-9.

5. Bond, A. J., \& Morrison-Saunders, A. (2009). Sustainability appraisal: Jack of al trades, master of none? Impact Assessment and Project Appraisal, 27(4), 321329. https://doi.org/10.3152/146155109X479422.

6. Bond, A., \& Morrison-Saunders, A. (2013). Challenges in determining the effectiveness of sustainability assessment. In A. Bond, A. Morrison-Saunders, \& R. Howitt (Eds.), Sustainability assessment: Pluralism, practice and progress (1st ed., pp. 37-50). Abingdon: Routledge.

7. Bueno, P. C., \& Magro, J. M. V. (2015). Setting the weights of sustainability criteria for the appraisal of transport projects. Transport, 30(3), 298-306. https://doi.org/10.3846/16484142.2015.1086890.

8. Bueno, P. C., Vassallo, J. M., \& Cheung, K. (2015). Sustainability assessment of transport infrastructure projects: A review of existing tools and methods. Transport Reviews, 35(5), 622-649. https://doi.org/10.1080/01441647.2015. 1041435.

9. Čadež, I., \& Hofmann, S. (2013). Anforderungen an die Bewertung der Nachhaltigkeit von Straß enbauwerken [sustainability assessment scheme for transport infrastructure projects]. Bautechnik, 90(10), 609-613. https://doi. org/10.1002/bate.201300048.

10. Chamorro, A., \& Tighe, S. (2009). Development of a management framework for rural roads in developing countries. Transportation Research Record, 2093, 99-107. https://doi.org/10.3141/2093-12.

11. Csete, M., \& Buzasi, A. (2016). Climate-oriented assessment of Main street design and development in Budapest. Journal of Environmental Engineering and Landscape Management, 24(4), 258-268. https://doi.org/10.3846/ 16486897.2016.1185431.

12. Damart, S., \& Roy, B. (2009). The uses of cost-benefit analysis in public transportation decision-making in France. Transport Policy, 16(4), 200-212. https://doi.org/10.1016/j.tranpol.2009.06.002.

13. De Ridder, W., Turpenny, J., \& Nilsson, M. (2007). A framework for tool selection and use for sustainability assessment. Journal of Environmental Assessment Policy and Management, 9(4), 432-441.

14. Devuyst, D. (1999). Sustainability assessment: The application of a methodological framework. Journal of Environmental Assessment Policy and Management, 1(4), 459-487 Retrieved from http://www.jstor.org/stable/ enviassepolimana.1.4.459.

15. Devuyst, D. (2001). Sustainability assessment at the local level. In D. Devuyst, L. Hens, \& W. de Lannoy (Eds.), How green is the City?: Sustainability assessment and the Management of Urban Environments (1st ed., pp. 175201). New York: Columbia University Press.

16. Dhakal, K. K. P., \& Oh, J. J. S. (2011). Integrating sustainability into highway projects: Sustainability indicators and assessment tool for Michigan roads. In T\&D/ congress 2011: Integrated transportation and development for a better tomorrow (pp. 987-996). https://doi.org/10.1061/41167(398)94.

17. Diaz-Sarachaga, J. M., Jato-Espino, D., \& Castro-Fresno, D. (2017). Methodology for the development of a new sustainable infrastructure rating system for developing countries (SIRSDEC). Environmental Science \& Policy, 69, 65-72. https://doi.org/10.1016/j.envsci.2016.12.010.

18. Dolnicar, S. (2002). A review of unquestioned standards in using cluster analysis for data-driven market segmentation. Faculty of Commerce-Papers, 273(December), 1-9 Retrieved from http://ro.uow.edu.au/commpapers/273/.

19. Dolnicar, S., Grün, B. Leisch, F. \& Schmidt, K. (2014). Required sample sizes for data-driven market segmentation analyses in tourism. Journal of Travel Research, 53(3), 296-306. https://doi.org/10.1177/0047287513496475.

20. Donnelly, A., Jones, M., O'Mahony, T., \& Byrne, G. (2007). Selecting environmental indicator for use in strategic environmental assessment. Environmental Impact Assessment Review, 27(2), 161-175. https://doi.org/10. 1016/j.eiar.2006.10.006

21. Enache, A., Kühmaier, M., Stampfer, K., \& Ciobanu, V. D. (2013). An integrative decision support tool for assessing Forest road options in a mountainous region in Romania. Croatian Journal of Forest Engineering, 34(1), 43-60.

22. Feitelson, E. (2002). Introducing environmental equity dimensions into the sustainable transport discourse: Issues and pitfalls. Transportation Research Part D: Transport and Environment, 7(2), 99-118. https://doi.org/10.1016/ S1361-9209(01)00013-X.

23. Fischer, T. B. (1999). The consideration of sustainability aspects in transport infrastructure related policies, plans and programmes: A comparative analysis of north West England, Noord-Holland and Brandenburg-Berlin. Journal of Environmental Planning and Management, 42, 189-219. https:// doi.org/10.1080/09640569911217. 
24. Flores, R. F., Montoliu, C. M. P. C. M.-P., \& Bustamante, E. G. (2016). Life cycle engineering for ROADS (LCE4ROADS), the new sustainability certification system for ROADS from the LCE4ROADS FP7 project. Transportation Research Procedia, 14, 896-905. https://doi.org/10.1016/.t.trpro.2016.05.069.

25. Freudenberger, L., Hobson, P. R., Rupic, S., Pe'er, G., Schluck, M., Sauermann, J., et al. (2013). Spatial road disturbance index (SPROADI) for conservation planning: A novel landscape index, demonstrated for the state of Brandenburg, Germany. Landscape Ecology, 28(7), 1353-1369. https://doi. org/10.1007/s10980-013-9887-8.

26. Friedrich, J. (2015). Integrating neglected ecological impacts of road transport into corporate management. Ecological Indicators, 54, 197-202. https://doi.org/10.1016/j.ecolind.2015.01.026.

27. Gasparatos, A., El-Haram, M., \& Horner, M. (2009). The argument against a reductionist approach for measuring sustainable development performance and the need for methodological pluralism. Accounting Forum, 33(3), 245256. https://doi.org/10.1016/j.accfor.2008.07.006.

28. Gibson, R. B. (2006). Sustainability assessment: Basic components of a practical approach. Impact Assessment and Project Appraisal, 24(3), 170-182. https://doi.org/10.3152/147154606781765147.

29. Gibson, R. B., Hassan, S., Holtz, S., Tansey, J., Whitelaw, G., \& Whitelaw, G. (2005). Sustainability assessment: Criteria, process and applications (1st ed.). London: Earthscan

30. Goodenough, R. A., \& Page, S. J. (1994). Evaluating the environmental impact of a major transport infrastructure project: The channel tunnel highspeed rail link. Applied Geography, 14(1), 26-50. https://doi.org/10.1016/01436228(94)90004-3.

31. Gough, D., Olver, S., \& Thomas, J. (2012). An introduction to systematic reviews. London: Sage Publications Ltd.

32. Grieco, M. (2015). Poverty mapping and sustainable transport: A neglected dimension. Research in Transportation Economics, 51, 3-9. https://doi.org/10. 1016/.j.retrec.2015.07.002.

33. Griffiths, K., Boyle, C., \& Henning, T. F. (2018). Sustainability rating tools for highway projects: The nature and the outcomes of use. Infrastructure Asset Management, 5(2), 35-44. https://doi.org/10.1680/jinam.17.00017.

34. Gudmundsson, H., Hall, R. P., Marsden, G., \& Zietsman, J. (2016). Sustainable transportation: Indicators, frameworks, and performance management. In Springer Texts in Business and Economics (Vol. 37). Heidelberg: SpringerVerlag.

35. Guijt, I., Moiseev, A., \& Prescott, A. (2001). IUCN resource kit for sustainability assessment. In IUCN monitoring and evaluation initiative. Gland and Cambridge: IUCN.

36. Gumus, S., Acar, H. H., \& Toksoy, D. (2008). Functional forest road network planning by consideration of environmental impact assessment for wood harvesting. Environmental Monitoring and Assessment, 142(1-3), 109-116. https://doi.org/10.1007/s10661-007-9912-y.

37. Hacking, T., \& Guthrie, P. (2008). A framework for clarifying the meaning of triple-bottom-line, integrated, and sustainability assessment. Environmental Impact Assessment Review, 28(2-3), 73-89. https://doi.org/10.1016/j.eiar.2007. 03.002.

38. Hameed, F., \& Hancock, K. (2014). Incorporating costs of life-cycle impacts into transportation program development. Transportation Research Record: Journal of the Transportation Research Board, 2453(571), 77-83. https://doi. org/10.3141/2453-10.

39. Hayati, E., Majnounian, B., Abdi, E., Sessions, J., \& Makhdoum, M. (2013). An expert-based approach to forest road network planning by combining Delphi and spatial multi-criteria evaluation. Environmental Monitoring and Assessment, 185(2), 1767-1776. https://doi.org/10.1007/s10661-012-2666-1.

40. Huang, S.-W., \& Tsou, K.-W. (2006). The multi-purpose greenways network planning in the Taichung metropolitan area, Taiwan. Urban Transport XI: Urban Transport and the Environment in the 21st Century, 1, 605-614. https:// doi.org/10.2495/UT060581.

41. Jørgensen, A., Le Bocq, A., Nazarkina, L., \& Hauschild, M. (2008). Methodologies for social life cycle assessment. International Journal of Life Cycle Assessment, 13(2), 96-103. https://doi.org/10.1065/lca2007.11.367.

42. Joumard, R., \& Nicolas, J.-P. (2010). Transport project assessment methodology within the framework of sustainable development. Ecological Indicators, 10(2), 136-142. https://doi.org/10.1016/j.ecolind.2009.04.002.

43. Keshkamat, S. S., Looijen, J. M., \& Zuidgeest, M. H. P. (2009). The formulation and evaluation of transport route planning alternatives: A spatial decision support system for the via Baltica project, Poland. Journal of Transport Geography, 17(1), 54-64. https://doi.org/10.1016/j.jtrangeo.2008.04.010.
44. Kokkaew, N., \& Rudjanakanoknad, J. (2017). Green assessment of Thailand's highway infrastructure: A green growth index approach. KSCE Journal of Civil Engineering, 21(7), 2526-2537. https://doi.org/10.1007/s12205-017-0923-0.

45. Kokoli, E., Chassiakos, A. P., \& Theodorakopoulos, D. D. (2007). Development of a highway sustainability index based on multi-attribute decision making. In B. H. V. Topping (Ed.), Proceedings of the 11th international conference on civil, structural and environmental engineering computing, civil-comp 2007 (pp. 1-20). Stirlingshire: Civil-Comp Press.

46. Kowalski, K., Stagl, S., Madlener, R., \& Omann, I. (2009). Sustainable energy futures: Methodological challenges in combining scenarios and participatory multi-criteria analysis. European Journal of Operational Research 197(3), 1063-1074. https://doi.org/10.1016/j.ejor.2007.12.049.

47. Krajangsari, T., \& Pongpeng, J. (2018). Sustainable infrastructure assessment model: An application to road projects (pp. 973-984). https://doi.org/10.1007/ s12205-019-1007-0.

48. Larrea-Gallegos, G., Vázquez-Rowe, I., \& Gallice, G. (2017). Life cycle assessment of the construction of an unpaved road in an undisturbed tropical rainforest area in the vicinity of Manu National Park, Peru. International Journal of Life Cycle Assessment, 22(7), 1109-1124. https://doi. org/10.1007/s11367-016-1221-7.

49. Lew, J. B., Anderson, J. L., \& Muench, S. T. (2016). Informing roadway sustainability practices by using Greenroads certified project data. Transportation Research Record: Journal of the Transportation Research Board, 2589, 1-13. https://doi.org/10.3141/2589-01.

50. Lidskog, R., \& Soneryd, L. (2000). Transport infrastructure investment and environmental impact assessment in Sweden: Public involvement or exclusion? Environment \& Planning A, 32(8), 1465-1480. https://doi.org/10. 1068/a32228.

51. Litman, T. (2007). Developing indicators for comprehensive and sustainable transport planning. Transportation Research Record, 10-15. https://doi.org/10. $3141 / 2017-02$

52. Lucas, K. (2006). Providing transport for social inclusion within a framework for environmental justice in the UK. Transportation Research Part A: Policy and Practice, 40(10), 801-809. https://doi.org/10.1016/j.tra.2005.12.005.

53. Mahmoudi, R., Shetab-Boushehri, S. N., Hejazi, S. R., \& Emrouznejad, A. (2019). Determining the relative importance of sustainability evaluation criteria of urban transportation network. Sustainable Cities and Society, 47(101493), 112. https://doi.org/10.1016/j.scs.2019.101493.

54. Manzo, S., \& Salling, K. B. (2016). Integrating life-cycle assessment into transport cost-benefit analysis. Transportation Research Procedia, 14, 273-282. https://doi.org/10.1016/j.trpro.2016.05.064.

55. Marzouk, M., El-zayat, M., \& Aboushady, A. (2017). Assessing environmental impact indicators in road construction projects in developing countries. Sustainability, 9(5), 843. https://doi.org/10.3390/su9050843.

56. Meulman, J., \& Heiser, W. (2013). IBM SPSS categories 24 IBM Coorporation.

57. Mitchard, N., Frost, L. C., Harris, J., Baldrey, S., \& Ko, J. (2011). Assessing the impact of road schemes on people and communities. Engineering Sustainability, 164(3), 185-196. https://doi.org/10.1680/2nsu.1000019.

58. Mooi, E., \& Sarstedt, M. (2011). A concise guide to market research: The process, data and methods using IBM SPSS statistics. In International journal of market research. https://doi.org/10.1007/978-3-642-12541-6.

59. Mooi, E., Sarstedt, M., \& Mooi-Reci, I. (2017). Cluster analysis. In Market research (the springer texts in business and economics) (pp. 313-366). https:// doi.org/10.1007/978-981-10-5218-7_9.

60. Muench, S. T., Anderson, J. L., \& Söderlund, M. (2010). Greenroads: A sustainability performance metric for roadways. Journal of Green Building, 5(2), 114-128. https://doi.org/10.3992/jgb.5.2.114.

61. Neri, M., Menconi, M. E., Vizzari, M., \& Mennella, V. G. G. (2010). Propuesta de una nueva metodología Para la ubicación de infraestructuras viarias ambientalmente sostenibles [a proposal of a new methodology for best location of environmentally sustainable roads infrastructures: Validation along the Fabriano-Muccia road]. Informes de la Construcción, 62(517), 101112. https://doi.org/10.3989/ic.09.043.

62. Petticrew, M., \& Roberts, H. (2006). Systematic reviews in the social sciences: A practical guide. Oxford: Blackwell Publishing.

63. Pope, J., Annandale, D., \& Morrison-Saunders, A. (2004). Conceptualising sustainability assessment. Environmental Impact Assessment Review, 24(6), 595-616. https://doi.org/10.1016/j.eiar.2004.03.001.

64. Pope, J., \& Morrison-Saunders, A. (2013). Pluralism in practice. In A. Bond, A. Morrison-Saunders, \& R. Howitt (Eds.), Sustainability assessment: Pluralism, practice and progress (1st ed., pp. 100-114). Abingdon: Routledge. 
65. Ramani, T. L., Zietsman, J., Gudmundsson, H., Hall, R. P., \& Marsden, G. (2011). Framework for sustainability assessment by transportation agencies. Transportation Research Record: Journal of the Transportation Research Board, 2242, 9-18. https://doi.org/10.3141/2242-02.

66. Rao, Y., Zhang, J., Xu, Q., \& Wang, S. (2018). Sustainability assessment of road networks: A new perspective based on service ability and landscape connectivity. Sustainable Cities and Society, 40, 471-483. https://doi.org/10. 1016/j.scs.2018.05.013.

67. Van Der Ree, R., Jaeger, J. A. G., Van Der Grift, E. A., \& Clevenger, A. P. (2011). Effects of roads and traffic on wildlife populations and landscape function : Road ecology is moving toward larger scales. Ecology and Society, 16(1), 48 Retrieved from http://www.ecologyandsociety.org/vol16/iss1/art48/.

68. Reid, L., Davis, A., \& Bevan, T. (2012). An approach for integrating sustainability into roadway project development. The 92nd Annual Meeting of the Transportation Research Board. Washington D.C.

69. Reza, B., Sadiq, R., \& Hewage, K. (2014). Emergy-based life cycle assessment (Em-LCA) for sustainability appraisal of infrastructure systems: A case study on paved roads. Clean Technologies and Environmental Policy, 16(2), 251-266. https://doi.org/10.1007/s10098-013-0615-5.

70. Sala, S., Ciuffo, B., \& Nijkamp, P. (2015). A systemic framework for sustainability assessment. Ecological Economics, 119, 314-325. https://doi. org/10.1016/j.ecolecon.2015.09.015

71. Salling, K. B., \& Pryn, M. R. (2015). Sustainable transport project evaluation and decision support: Indicators and planning criteria for sustainable development. International Journal of Sustainable Development and World Ecology, 22(4), 346-357. https://doi.org/10.1080/13504509.2015.1051497.

72. Santos, G., Behrendt, H., \& Teytelboym, A. (2010). Part II: Policy instruments for sustainable road transport. Research in Transportation Economics, 28(1), 46-91. https://doi.org/10.1016/j.retrec.2010.03.002.

73. Santos, J., Ferreira, A., \& Flintsch, G. (2015). A life cycle assessment model for pavement management: Methodology and computational framework International Journal of Pavement Engineering, 16(3), 268-286. https://doi.org/ 10.1080/10298436.2014.942861.

74. Sheate, W. R. (2009). The evolving nature of environmental assessment and management: Linking tools to help deliver sustainability. In W. R. Sheate (Ed. ). Tools, techniques and approaches for sustainability (1st ed., pp. 1-30). https://doi.org/10.1142/7519.

75. Sinharay, S. (2010). An overview of statistics in education. In International encyclopedia of education (pp. 1-11). https://doi.org/10.1016/B978-0-08044894-7.01719-X

76. Stripple, H. (2001). Life cycle assessment of road a pilot study for inventory analysis (2nd ed.). Gothenburg: Swedish Environmental Research Institute Ltd Box.

77. Svarstad, H., Petersen, L. K., Rothman, D., Siepel, H., \& Wätzold, F. (2008). Discursive biases of the environmental research framework DPSIR. Land Use Policy, 25(1), 116-125. https://doi.org/10.1016/j.landusepol.2007.03.005.

78. Tatari, O., Egilmez, G., \& Kurmapu, D. (2016). Socio-eco-efficiency analysis of highways: A data envelopment analysis. Journal of Civil Engineering and Management, 22(6), 747-757. https://doi.org/10.3846/13923730.2014.914079.

79. Tatari, O., \& Kurmapu, D. (2011). Sustainability assessment of highways: A Malmquist index of U.S. states. In Proceedings of the 2011 IEEE international symposium on sustainable systems and technology, ISSST (pp. 1-6). https:// doi.org/10.1109/ISSST.2011.5936849.

80. Thérivel, R., Christian, G., Craig, C., Grinham, R., Mackins, D., Smith, J. L., et al (2009). Sustainability-focused impact assessment: English experiences. Impact Assessment and Project Appraisal, 27(2), 155-168. https://doi.org/10. 3152/146155109X438733.

81. Thorne, J. H., Huber, P. R., O'Donoghue, E., Santos, M. J., O'Donoghue, E., \& Santos, M. J. (2014). The use of regional advance mitigation planning (RAMP) to integrate transportation infrastructure impacts with sustainability; a perspective from the USA. Environmental Research Letters, 9(6), 1-13. https://doi.org/10.1088/1748-9326/9/6/065001.

82. Verheem, R. A. A. (2002). Recommendations for sustainability assessment in the Netherlands Retrieved July 18, 2019, from environmental impact assessment in the Netherlands: Views from the Commision for EIA in 2002 website: http://www.commissiemer.nl/docs/mer/diversen/eia_views_2002. pdf.

83. Willetts, R., Burdon, J., Glass, J., \& Frost, M. (2010). Environmental and sustainability impact assessment of infrastructure in the United Kingdom. Transportation Research Record: Journal of the Transportation Research Board, 2158, 143-150. https://doi.org/10.3141/2158-18.
84. Zinke, T., Schmidt-Thrö, G., \& Ummenhofer, T. (2012). Entwicklung und Verwendung von externen Kosten für die Nachhaltigkeitsbewertung von Verkehrsinfrastruktur [development and application of external costs as part of the sustainability assessment of transportation infrastructure]. Beton- und Stah/betonbau, 107(8), 524-532. https://doi.org/10.1002/best.201200021.

\section{Publisher's Note}

Springer Nature remains neutral with regard to jurisdictional claims in published maps and institutional affiliations.

\section{Submit your manuscript to a SpringerOpen ${ }^{\circ}$ journal and benefit from:}

- Convenient online submission

- Rigorous peer review

- Open access: articles freely available online

High visibility within the field

- Retaining the copyright to your article

Submit your next manuscript at $\boldsymbol{\nabla}$ springeropen.com 